\title{
STABILITAS FISIK DAN ANTIOKSIDAN MIKROEMULSI MINYAK NILAM DENGAN VARIASI TWEEN 80 DAN PEG 400
}

\author{
Physical Stability And Antioxidant Activity Microemulsion Of Patchouli Oil With Tween 80 And PEG \\ 400 Variation
}

\author{
Ayu Shabrina $^{1 *}$, Annisa Rahayuning Pratiwi ${ }^{1}$, Mimiek Murrukmihadi $^{2}$ \\ ${ }^{1}$ Fakultas Farmasi, Universitas Wahid Hasyim, Semarang \\ ${ }^{2}$ Fakultas Farmasi, Universitas Gadjah Mada, Yogyakarta \\ *Koresponden E-mail : shabrina@unwahas.ac.id
}

DOI: https://doi.org/10.32382/mf.v16i2.1720

\begin{abstract}
Patchouli oil (Pogostemon cablin Benth.) has potential as an antioxidant and high volatility due to air and light, therefore it needs to be formulated in the form of a microemulsion. This research aims to determine the physical stability and antioxidant microemulsion of patchouli oil with different concentrations of Tween 80 and PEG 400. Microemulsions was prepared with patchouli oil content of 5\% along with different concentration of Tween 80: PEG 400 were F1 (26\%: 13\%), F2 (13\%: 26\%) and for F3 (26\%: 26\%). The patchouli oil microemulsion was tested for physical stability by the cycling test method using a climatic chamber at a temperature of $40^{\circ} \mathrm{C} \pm 2^{\circ} \mathrm{C}$ and $4^{\circ} \mathrm{C} \pm 2^{\circ} \mathrm{C}$ for 6 cycles. Furthermore, the tests include organoleptic, homogeneity, viscosity, $\mathrm{pH}$, and separation. The antioxidant test was carried out using the DPPH method, and the quantitative data on physical stability and antioxidants were analyzed by a $t$-dependent test. The stability test results showed that F2 and F3 had decreased viscosity after 6 storage cycles $(p<0.05)$. The results of the homogeneity, $p H$ and separation tests did not experience significant differences. The test results of patchouli oil microemulsion antioxidant activity showed no change in antioxidant activity during 6 storage cycles with the mean inhibition percent before and after the cycling test was 73,13 \pm 0,38\%. Patchouli oil microemulsion with tween 80: PEG 400 26\%: 13\% showed the most stable physical quality and antioxidant properties.
\end{abstract}

Keywords : Microemulsion, Patchouli Oil, Physical Stability, Antioxidants

\begin{abstract}
ABSTRAK
Minyak nilam (Pogostemon cablin Benth.) berpotensi sebagai antioksidan dan memiliki laju volatilitas tinggi akibat udara dan cahaya sehingga perlu diformulasikan dalam bentuk mikroemulsi. Penelitian ini bertujuan untuk mengetahui stabilitas fisik dan antioksidan mikroemulsi minyak nilam dengan variasi konsentrasi tween 80 dan PEG 400. Mikroemulsi dibuat dengan kadar minyak nilam 5\% dan variasi konsentrasi campuran tween 80:PEG 400 adalah untuk F1 (26\%:13\%) dan F2 (13\%:26\%) serta untuk F3 (26\%:26\%). Mikroemulsi minyak nilam diuji stabilitas fisik dengan metode cycling test menggunakan climatic chamber pada suhu $40^{\circ} \mathrm{C} \pm 2{ }^{\circ} \mathrm{C}$ dan $4{ }^{\circ} \mathrm{C} \pm 2{ }^{\circ} \mathrm{C}$ selama 6 siklus. Pengujian meliputi organoleptis, homogenitas, viskositas, $\mathrm{pH}$, dan uji pemisahan. Uji antioksidan dilakukan menggunakan metode DPPH. Data kuantitatif dari stabilitas fisik dan antioksidan dianalisis dengan uji $t$-dependent. Hasil uji stabilitas menunjukkan F2 dan F3 mengalami penurunan viskositas setelah 6 siklus penyimpanan (p < 0,05). Hasil uji homogenitas,pH dan uji pemisahan tidak mengalami perbedaan bermakna. Hasil uji aktivitas antioksidan mikroemulsi minyak nilam menunjukkan tidak terjadi perubahan aktivitas antioksidan selama 6 siklus penyimpanan dengan rerata persen inhibisi sebelum dan sesudah cycling test adalah 73,13 \pm 0,38 \%. Mikroemulsi minyak nilam F1 dengan tween 80: PEG 400 26\%:13\% menunjukkan Mutu fisik dan sifat antioksidan yang paling stabil.
\end{abstract}

Kata kunci : Mikroemulsi, Minyak Nilam, Stabilitas Fisik, Antioksidan

\section{PENDAHULUAN}

Kulit memiliki sejumlah antioksidan endogen yang dapat melindungi kulit dari kerusakan oksidatif. Kulit secara berkesinambungan terpapar oxidative stress baik secara endogen maupun dari lingkungan sekitar. Hal ini menyebabkan terbentuknya Reactive Oxygen Species (ROS) dan pada akhirnya 
menyebabkan kerusakan kulit (Choi et al., 2005). Antioksidan diperlukan bagi tubuh untuk mengatasi paparan tersebut. Antioksidan bisa berasal dari suplemen makanan maupun kosmetik. Antioksidan yang dihasilkan tubuh manusia tidak cukup untuk melawan radikal bebas, untuk itu tubuh memerlukan asupan antioksidan dari luar (Tisnadjaja, 2012).

Tanaman di Indonesia yang berpotensi sebagai antioksidan salah satunya adalah dari tanaman nilam (Pogostemon cablin Benth.) yang menghasilkan minyak atsiri dengan konsentrasi yang tinggi. Minyak nilam atau yang dikenal dengan patchouli oil dalam industri farmasi telah banyak digunakan untuk sediaan kosmetik, parfum, sabun, dan sediaan topikal farmasi lainnya (Nuryani, 2006). Menurut Hussain et al.., (2011) minyak nilam mempunyai IC $_{50}$ paling rendah dibandingkan dengan minyak esensial lainnya yang berasal dari keluarga Lamiaceae dimana nilai $\mathrm{IC}_{50}$ adalah $225,7 \pm 6,7 \mu \mathrm{g} / \mathrm{mL}$. Bae (2009) menyatakan bahwa minyak nilam dapat digunakan sebagai whitening agent yang dapat menghambat sintesis melanin dan dapat memperlemah aktivitas ROS dengan nilai IC $_{50}$ $3,14 \pm 0,12 \mu \mathrm{g} / \mathrm{mL}$. Soh (2018) menyatakan bahwa minyak nilam memiliki kemampuan sebagai antioksidan dengan nilai $\mathrm{IC}_{50} 1,538 \mathrm{ppm}$. Smith (2019) menyatakan bahwa minyak nilam memiliki laju volatilitas yang tinggi sehingga bila disimpan pada suhu ruang atau digunakan langsung, minyak nilam akan menguap dan aktivitasnya menurun. Setya (2011) menyatakan bahwa mnyak nilam mudah menguap tanpa mengalami dekomposisi kimia. Irawati (2017) menyatakan bahwa minyak nilam dalam mikroemulsi dengan VCO dan tween 80 memiliki sifat fisik yang baik. Hal ini menyebabkan minyak nilam perlu difromulasikan ke dalam berbagai bentuk sediaan topikal salah satunya adalah sediaan mikroemulsi.

Mikroemulsi mempunyai beberapa keuntungan yaitu stabil secara termodinamika, viskositas rendah, dan preparasi mudah (Yuwanti et al., 2011). Penelitian Elfiyani dkk. (2017) menunjukkan bahwa peningkatan konsentrasi kombinasi surfaktan dan kosurfaktan dapat membentuk sistem mikroemulsi yang stabil. Daud dkk. (2017) dan Sisak dkk. (2017) juga menyatakan bahwa tween 80 dan PEG 400 sebagai emulgator menghasilkan mikroemulsi yang stabil. Kombinasi surfaktan-kosurfaktan tween 80-PEG 400 memberikan hasil mikroemulsi yang jernih dengan persen transmitan 99,7\% (Sari dkk., 2019). Priani dkk (2019) mikroemulsi dengan kombinasi surfaktan dan kosurfaktan tween 80 dan PEG 400 memiliki karakteristik fisik yaitu tingkat kejernihan dan transparansi yang baik Kombinasi Tween 80 dan PEG 400 dalam mikroemulsi mampu membentuk emulsi yang stabil selama 1 tahun Natasya (2018). Stabilitas produk diperlukan untuk memastikan integritas fisik produk kosmetik dalam kondisi penyimpanan dan penggunaan yang sesuai serta memastikan stabilitas kimia, stabilitas mikrobiologis, dan kesesuaian antara isi dan wadah sehingga produk dapat memberikan efek semestinya (CTFA, 2004).

maka Berdasarkan uraian tersebut di atas mikroemulsi minyak nilam dan dilakukan uji stabilitasnya meliputi organoleptis, homogenitas, $\mathrm{pH}$, viskositas, pemisahan dengan uji sentrifugasi serta stabilitas antioksidan dengan metode DPPH. Berdasarkan latar belakang di atas maka dapat dirumuskan: bagaimana stabilitas fisik dan antioksidan mikroemulsi minyak nilam dengan variasi konsentrasi tween 80 dan PEG 400? Penelitian ini bertujuan untuk membuat formula dan mengkaji stabilitas fisik dan antioksidan mikroemulsi minyak nilam dengan variasi konsentrasi tween 80 dan PEG 400 sehingga dihasilkan formula mikroemulsi minyak nilam yang paling stabil

\section{METODE}

\section{Jenis dan waktu Penelitian}

Jenis penelitian ini merupakan penelitian eksperimen laboratorium yang bertujuan untuk menguji stabilitas fisik dan antioksidan mikroemulsi minyak nilam. Penelitian ini dilakukan pada bulan November 2019 hingga Januari 2020. Penelitian dilakukan di Laboratorium Teknologi Farmasi Universitas Wahid Hasyim Semarang.

\section{Alat dan bahan}

Alat yang digunakan dalam penelitian ini adalah magnetic stirrer, climatic chamber, hot plate, neraca analitik, alat-alat gelas, $\mathrm{pH}$ meter, viskometer Rion, sentrifugator dan votex. Bahan yang digunakan dalam penelitian ini adalah minyak nilam yang dari Bogor yang dilengkapi dengan CoA, isopropyl miristat, tween 80, PEG 400 dan DPPH.

\section{Prosedur kerja \\ Pembuatan mikroemulsi minyak nilam}

Rancangan formula mikroemulsi minyak nilam dapat dilihat pada tabel 1 . 
Tabel 1. Rancangan formula mikroemulsi minyak nilam

\begin{tabular}{cccc}
\hline Bahan $(\%$ v/v) & Formula I & Formula II & Formula III \\
\hline Minyak Nilam & 5 & 5 & 5 \\
\hline Aquadest & 10 & 10 & 10 \\
\hline Tween 80 & 26 & 13 & 26 \\
\hline PEG 400 & 13 & 26 & 26 \\
\hline Isopropil Miristat hingga & 100 & 100 & 100 \\
\hline
\end{tabular}

Mikroemulsi minyak nilam dibuat dengan mencampurkan fase air (PEG 400 dan aquadest) dan fase minyak (minyak nilam, isopropil miristat, dan tween 80) saat keduanya telah mencapai suhu $70{ }^{\circ} \mathrm{C}$. Pencampuran dilakukan menggunakan magnetic stirrer dengan kecepatan $550 \mathrm{rpm}$ selama 30 menit hingga terbentuk mikroemulsi yang jernih (Prihantini, 2018).

\section{Pengujian stabilitas fisik mikroemulsi minyak nilam}

Uji stabilitas dilakukan dengan metode cycling test selama 6 siklus. Satu siklus dihitung bila sediaan telah disimpan pada suhu $40 \pm 2{ }^{\circ} \mathrm{C}$ selama 24 jam dan suhu $4 \pm 2{ }^{\circ} \mathrm{C}$ selama 24 jam. Evaluasi karakteristik fisik dilakukan meliputi:

a. Uji organoleptis dan homogenitas

Pengamatan organoleptis dan homogenitas dapat dilihat dengan adanya pemisahan fase atau pecahnya mikroemulsi, ketengikan, dan perubahan warna yang diamati secara visual (Putri, 2014).

b. Uji pH

Mikroemulsi di ambil sebanyak $10 \mathrm{~mL}$ dimasukkan ke dalam wadah, kemudian $\mathrm{pH}$ diukur dengan menggunaka $\mathrm{pH}$ meter (Suryani et al., 2017)

c. Uji Viskositas

Uji viskositas dilakukan dengan viskometer rion dimana mikroemulsi dimasukkan ke dalam cup untuk pengujian lalu pada alat digunakan rotor no 3 . Rotor yang telah dipasang dimasukkan ke dalam cup yang sudah berisi sediaan. Alat dinyalakan dan rotor akan berputar, nilai viskositas akan muncul pada viskometernya. (Suryani et al., 2017)

d. Uji pemisahan fase

Metode sentrifugasi dilakukan dengan melakukan sentrifugasi terhadap sediaan mikroemulsi selama 30 menit pada kecepatan $3.000 \mathrm{rpm}$. Sediaan dikatakan stabil jika tidak terjadi pemisahan fasa setelah sentrifugasi (Aryani, 2015).

\section{Pengujian aktivitas antioksidan}

Pengujian antioksidan sediaan mikroemulsi minyak nilam dilakukan dengan memasukkan sebanyak $2 \mathrm{~mL}$ sediaan mikroemulsi minyak nilam, $2 \mathrm{~mL}$ DPPH 0,1 $\mathrm{mM}$, dan $4 \mathrm{~mL}$ metanol, kemudian divorteks hingga homogen dan dibaca pada panjang gelombang $516 \mathrm{~nm}$. Sediaan mikroemulsi diuji sebelum dan setelah disimpan pada cycling test selama 6 siklus.

\section{Pengolahan dan analisis data}

Data stabilitas selama 6 siklus yang diperoleh dari uji $\mathrm{pH}$, viskositas dan antioksidan dianalisis secara statistik dengan uji t-dependent untuk melihat ada atau tidaknya perubahan selama pengujian.

\section{HASIL}

\section{Uji Stabilitias Fisik}

Uji organoleptis dan homogenitas

Hasil uji organoleptis meliputi warna, bau dan homogenitas dapat dilihat pada tabel 2 . 
Tabel 2. Hasil pengamatan organoleptis mikroemulsi minyak nilam dengan variasi konsentrasi tween 80 dan PEG 400

\begin{tabular}{|c|c|c|c|c|c|c|c|c|}
\hline \multirow{3}{*}{ Formula } & \multicolumn{8}{|c|}{ Pengamatan } \\
\hline & \multicolumn{4}{|c|}{ Sebelum cycling test } & \multicolumn{4}{|c|}{ Setelah cycling test } \\
\hline & Warna & Bau & Konsistensi & Tampilan & Warna & $\mathrm{Bau}$ & Konsistensi & Tampilan \\
\hline F1 $(2: 1)$ & \multirow{3}{*}{$\begin{array}{c}\text { Kuning } \\
\text { pucat }\end{array}$} & \multirow{3}{*}{$\begin{array}{c}\text { Khas } \\
\text { patchouli }\end{array}$} & \multirow{3}{*}{$\begin{array}{c}\text { Agak } \\
\text { kental, } \\
\text { berminyak }\end{array}$} & \multirow{3}{*}{ Homogen } & \multirow{3}{*}{$\begin{array}{c}\text { Kuning } \\
\text { pucat }\end{array}$} & \multirow{3}{*}{$\begin{array}{c}\text { Khas } \\
\text { patchouli }\end{array}$} & Agak & \multirow[t]{3}{*}{ Homogen } \\
\hline $\mathrm{F} 2(1: 2)$ & & & & & & & kental, & \\
\hline F3 (1:1) & & & & & & & berminyak & \\
\hline
\end{tabular}

\section{Uji pH}

Hasil uji pH dapat dilihat pada tabel sebagai berikut

Tabel 3. Hasil uji pH mikroemulsi minyak nilam dengan variasi tween 80 dan PEG 400

\begin{tabular}{ccc}
\hline Formula & Sebelum cycling test & Setelah cycling test \\
\cline { 2 - 3 } & $\mathrm{pH} \pm \mathrm{SD}$ & $\mathrm{pH} \pm \mathrm{SD}$ \\
\hline F1 $(2: 1)$ & $7,00 \pm 0,02$ & $6,98 \pm 0,02$ \\
\hline F2 $(1: 2)$ & $6,93 \pm 0,00$ & $6,95 \pm 0,03$ \\
\hline F3 $(1: 1)$ & $6,98 \pm 0,01$ & $7,01 \pm 0,04$ \\
\hline
\end{tabular}

\section{Uji viskositas}

Hasil uji viskositas dapat dilihat pada tabel sebagai berikut

Tabel 4. Hasil uji viskositas mikroemulsi minyak nilam dengan variasi tween 80 dan PEG 400

\begin{tabular}{lll}
\hline \multirow{2}{*}{ Formula } & \multicolumn{1}{c}{ Sebelum cycling test } & Setelah cycling test \\
\cline { 2 - 3 } & Viskositas \pm SD $(\mathrm{dPas})$ & Viskositas \pm SD $(\mathrm{dPas})$ \\
\hline F1 $(2: 1)$ & $1,49 \pm 0,10$ & $1,51 \pm 0,10$ \\
\hline F2 $(1: 2)$ & $1,70 \pm 0,10$ & $1,43 \pm 0,01$ \\
\hline F3 $(1: 1)$ & $1,83 \pm 0,06$ & $1,51 \pm 0,06$ \\
\hline
\end{tabular}

\section{Uji pemisahan}

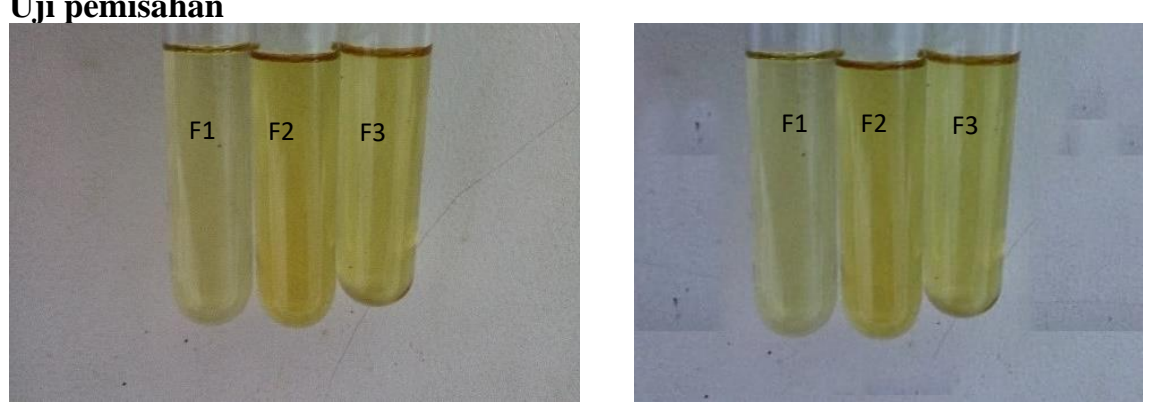

Gambar 1. Hasil uji pemisahan sebelum cycling test (a) dan setelah cycling test (b)

\section{Uji antioksidan dengan DPPH}

Hasil uji aktivitas antioksidan dapat dilihat pada tabel sebagai berikut

Tabel 5. Hasil uji aktivitas antiokidan mikroemulsi minyak nilam dengan variasi tween 80 dan PEG 400

\begin{tabular}{l|cc}
\multirow{2}{*}{ Formula } & \multicolumn{1}{c}{ Sebelum cycling test } & Setelah cycling test \\
\cline { 2 - 3 } & Persen Inhibisi \pm SD $(\%)$ & Persen Inhibisi \pm SD $(\%)$ \\
\hline F1 $(2: 1)$ & $73,40 \pm 1,84$ & $73,20 \pm 1,55$ \\
\hline F2 $(1: 2)$ & $73,20 \pm 1,70$ & $72,58 \pm 1,42$ \\
\hline F3 $(1: 1)$ & $73,60 \pm 1,67$ & $72,80 \pm 1,38$ \\
\hline
\end{tabular}




\section{PEMBAHASAN}

Minyak nilam dalam formulasi ini berfungsi sebagai zat aktif karena memiliki beberapa aktivitas farmakologi seperti antibaketri, antifungi, dan antioksidan (Zhao dkk., 2005). IPM dipilih sebagai fasa minyak karena merupakan minyak non-trigliserida dengan berat molekul rendah dengan karakteristik polaritas tinggi, tegangan antar permukaan rendah dan viskositas rendah. Minyak dengan karakteristik seperti ini sangat menguntungkan dalam pembuatan mikroemulsi karena lebih mudah mengasilkan ukuran globul mikro dibandingkan dengan minyak mineral yang memiliki ukuran molekul besar dengan rantai asam lemak hidrokarbon panjang (Wang, 2014). Tween 80 dipilih sebagai surfaktan dalam formula merupakan surfaktan nonionik dengan toksisitas yang rendah dibandingkan dengan surfaktan anionik dan kationik (Azeem, 2009). PEG 400 dipilih sebagai kosurfaktan dalam formula karena dapat memberikan emulsi yang jernih dan stabil. Penggunaan PEG 400 sebagai kosurfaktan bertujuan untuk menurunkan tegangan antar permukaan air dan minyak dan meningkatkan fluiditas diantara kedua permukaan tersebut sehingga partisi diantara keduanya meningkat dan kedua fase yang semula tidak saling bercampur dapat saling tercampurkan. Selain itu, PEG 400 juga dapat berperan sebagai pelembut dan peningkat penetrasi di dalam formula sediaan topikal (Azeem, 2009). Pembuatan mikroemulsi minyak nilam dibuat dengan adanya pemanasan bertujuan menurunkan viskositas dan tegangan permukaan dari kedua fasa agar pencampuran lebih mudah dan homogeny (Delmas dkk., 2011).

Hasil uji organoleptis dari ketiga formula mikroemulsi tidak ada perbedaan. Mikroemulsi yang terbentuk agak kental, warnanya kuning pucat dan jernih serta memiliki bau khas aromatik nilam. Hasil uji homogenitas menunjukkan mikroemulsi dari F1, F2, dan F3 homogen, ditunjukkan dengan sediaan yang jernih. Hasil penelitian ini sejalan dengan penelitian Pareta (2020) bahwa campuran tween 80 dan PEG 400 dapat menghasilkan campuran yang jernih dikarenakan adanya interaksi gugus hidroksi pada bagian hidrofil dari kedua senyawa tersebut. Pareta (2020) menyatakan bahwa Tween 80 memiliki 3 gugus hidroksi dan PEG 400 memiliki 2 gugus hidroksi.

Hasil uji pH mikroemulsi minyak nilam $\mathrm{F} 1, \mathrm{~F} 2$, dan F3 menunjukkan bahwa $\mathrm{pH}$ sesuai dengan $\mathrm{pH}$ sediaan topikal yaitu pada kisaran $\mathrm{pH}$ 4,5 - 8,0 (Liony, 2014). $\mathrm{pH}$ yang terlalu asam dapat menyebabkan iritasi sedangkan $\mathrm{pH}$ yang terlalu basa dapat menyebabkan kulit bersisik (Liony, 2014).

Uji viskositas bertujuan untuk mengetahui kekentalan dari sediaan mikroemulsi. Viskositas adalah sifat yang menentukan besar daya tahannya terhadap gaya geser (Kim, 2005). F2 dan F3 menunjukkan adanya kenaikan viskositas yang signifikan ( $\mathrm{p}<$ $0,05)$. Penurunan viskositas dapat diakibatkan suhu tinggi saat cycling test sehingga akan memperbesar globul sehingga jarak antar globul akan semakin besar yang menyebabkan viskositas semakin menurun (Lachman dkk., 1994). Penurunan viskositas dapat terjadi akibat adanya shearing terhadap surfaktan dengan rantai panjang yaitu tween 80 sehingga molekul penyusunnya menjadi tidak beraturan (Martin \& Cammarata, 1993). Hal ini sejalan dengan penelitian Pratiwi (2019) bahwa viskositas mikroemulsi minyak nilam menurun setelah 12 hari penyimpanan.

Uji pemisahan menggunakan sentrifugasi bertujuan untuk mengetahui kestabilan sediaan mikroemulsi dengan cara mengamati pemisahan fase setelah disentrifugasi. Uji ini diperlukan untuk mengetahui efek guncangan pada saat transport produk terhadap tampilan fisik produk (Aryani, 2015). Hasil pengujian pemisahan dengan sentrifugasi menunjukkan bahwa sediaan mikroemulsi minyak nilam stabil, tetap jernih, dan tidak terjadi pemisahan fase atau terbentuk endapan. Hasil penelitian Irawati dkk. (2017) menyatakan bahwa mikroemulsi minyak nilam dengan tween 80 memiliki karakteristik fisik yang baik dan tidak mengalami pemisahan pada uji sentrifugasi. Febriyenti dkk. (2019) menyatakan bahwa penggunaan tween 80 dalam gel minyak nilam memberikan hasil tidak adanya perbedaan bermakna pada warna, $\mathrm{pH}$ dan viskositas sediaan.

Uji aktivitas antioksidan menunjukkan bahwa terjadi penurunan aktivitas antioksidan namun tidak berbeda bermakna sebelum dan setelah dilakukan cycling test. Rerata hasil persen inhibisi secara keseluruhan adalah 73,13 $\pm 0,38 \%$. Hal ini sejalan dengan penelitian $\underline{\mathrm{Xu}}$ dkk. (2017) bahwa aktivitas antioksidan dari patchouli alcohol dapat menurun pada penyimpanan akibat karakteristik minyak nilam yang mudah menguap pada suhu ruang. Suprijono (2015) menyatakan bahwa konsentrasi minyak nilam sebanyak $15 \%$ memiliki nilai EC50 sebesar $19,35 \%$ dan tidak berbeda signifikan dengan BHT 5\%. Dechayont dkk. (2017) menyatakan bahwa patchouli alcohol dari minyak nilam memiliki IC50 18 ppm dan 19 ppm dengan metode uji DPPH dan ABTS. Aktivitas 
antioksidan dari minyak nilam berasal dari kandungannya yang sebagian besar terdiri dari senyawa siklik tak jenuh sehingga memungkinkan komponen tersebut sebagai pendonor proton ke DPPH sehingga terbentuk DPPH non-radikal. Senyawa terpenoid yang ada dalam minyak nilam ini merupakan senyawa monoterpen dan sesquiterpen (Hussain dkk., 2011). Bozin dkk. (2006) menyatakan bahwa aktivitas antioksidan dari minyak nilam dipengaruhi oleh senyawa seperti $\alpha$-pinene dan $\beta$-pinene. Minyak nilam mengandung monoterpen yang aktif sebagai antioksidan yaitu patchouli alcohol termasuk dalam sesquiterpen teroksigenasi yang pro-oksidan (Halimah dan Yulfi, 2011) sehingga minyak nilam memiliki aktifitas antioksidan sangat kuat. Penelitian ini sejalan dengan Adhavan dkk. (2017) bahwa dengan memperkecil ukuran globul minyak nilam melalui pembentukan nanoemulsi menggunakan surfaktan-kosurfatkan dari golongan tween dan etilen glikol dapat meningkatkan stabilitas minyak nilam selama 45 hari dan meningkatkan aktivitas dari minyak nilam.

\section{KESIMPULAN}

Berdasarkan hasil penelitian yang dilakukan, maka dapat disimpulkan bahwa formula mikroemulsi minyak nilam dengan perbandingan tween 80: PEG 400 yaitu 1:1 menunjukkan hasil yang paling stabil dengan warna kuning pucat, jernih dan menunjukkan persen inhbisi terhadap DPPH dengan rerata keseluruhan persen inhibisi adalah 73,13 \pm $0,38 \%$.

\section{SARAN}

Disarankan bagi peneliti selanjutnya untuk membuat formulasi mikroemulsi minyak nilam dengan surfaktan-ko surfaktan dari golongan tween dan etilen glikol lain yang dapat meningkatkan stabilitas minyak nilam dalam penyimpanan.

\section{DAFTAR PUSTAKA}

Adhavan, P., Kaur, G., Princy, A., Murugan, R., 2017, Essential oil nanoemulsion of wild patchouli attenuate multi-drug resistant gram-positive, gramnegative and Candida albicans, Inustrial Crops and Products, 100, 106-116.

Aryani, R., 2015, Formulasi Dan Uji Stabilitas Krim Kombinasi Alfa Tokoferol Asetat Dan Etil Vitamin C Sebagai Pelembab Kulit, Jurnal Kesehatan
Bakti Tunas Husada, 14(1), 38 - 46.

Azeem, A., Rizwan, M., Ahmad., Khan, Khar, Aqil, M., dan Talegaonkar, S., 2008, emerging Role of Microemulsion in Cosmetics Recent Patentson Drug Delivery and Formulation, Departement of Pharmaceutics Faculty of Pharmacy, New Delhi, 275 -276 .

Bae, S.Y., Lee, E.J., Son, H., dan Lee, Y.H., 2009, The Inhibitory Effects of Pogostemon cablin Bentham Extract on Melanogenesis, Journal of the Society of Cosmetic Scientists of Korea, vol. 35 (1), 33 - 39.

Bozin, B.N., Mimica, N., Simin, dan Anackov, G., 2006, Characterization of the volatile composition of essential oils of some Lamiaceae species and the antimicrobial and antioxidant activities of the entire oils. Journal of Agriculture and Food Chemistry, 54: 1822-1828.

Choi, C.W., Choi, J.W., Park K.C., Youn, S.W., 2011, Facial Sebum Affects the Development of Acne Especially The Distribution of Inflammatory Acne, Journal of the European Academy of Dermatology Venerology, 17, 1-5.

CTFA, 2014, Guideline on Stability Testing of Cosmetic product, The European Cosmetic Toiletry and Perfumery Association, Europe.

Daud, N.S. dan Evi, S., 2017, Formulasi Emulgel Antijerawat Minyak Nilam (Patchouli oil) Menggunakan Tween 80 dan Span 80 sebagai Pengemulsi dan HPMC sebagai Basis Gel, Jurnal Mandala Pharmacon Indonesia, 3, 21-25.

Dechayont, B., Ruamdee, P., Poonnaimuang, S., Mokmued, K., Orn, J.C., 2017, Antioxidant and Antimicrobal Activity of Pogostemon cablin Benth., Journal of Botany, Vol. 2017, 1-6.

Delmas, T., Piraux, H., Couffin, A. C., Texier, I., Vinet, F., Poulin, P., \& Bibette, J., 2011, How to prepare and stabilize very small nanoemulsions, Langmuir, 27(5), 1683-1692.

Elfiyani, R., Anisa, A., dan Septian, S. P., 2017, Effect of Using the Combination of Tween 80 and Ethanol on the Forming and Physical Stability of 
Microemulsion of Eucalyptus Oil as Antibacterial, Journal of Young Pharmacist, 9(1), 1-2.

Febriyenti, Putri, R.F., Suharti, N., 2019, Formulation and Evaluation of Patchouli Oil Gel for Burn Wound, Jurnal Sains Farmasi dan Klinis, 6 (3), 191-194.

Halimah, D.P.P. dan Zetra,Y., 2011, Minyak Atsiri dari Tanaman Nilam (Pogostemon cablin Benth.) melalui Metode Fermentasi dan Hidrodistilasi serta Uji Bioaktivitasnya, Fakultas Matematika dan Ilmu Pengetahuan Alam Institut Teknologi Sepuluh November.

Hanani, E., 2005, Identifikasi Senyawa Antioksidan dalam Spons Callyspongia SP Dari Kepulauan Seribu, Majalah Ilmu Kefarmasian.

Hussain, A.I., Farooq, A., Tahira, I., dan Ijaz, A.B., 2011, Antioxidant Attributes of Four Lamiaceae Essential Oils, Pakistan Journal of Botany, 43(2): 1315 - 1321.

Irawati, S.P., Dina, R., dan Mia, F., 2017, Karakteristik Mikroemulsi Minyak Nilam (Pogostemon cablin Benth.) Dengan Pembawa Virgin Coconut Oil (VCO), Polisorbat 80, dan Sorbitol, Jurnal Pharmascience, 4, 109 - 115.

Kim, C.J., 2005, Advanced Pharmaceutics, Physicochemical Principles, CRS Press LLC, Florida, 214 - 235.

Liony, B., 2014, Pengaruh Penambahan Esktrak Gambir Terhadap Sifat Fisik dan Nilai Sun Protection Factor (SPF) pada hasil Jadi Krim Tabir Surya, $e$ Journal, 209 - 216.

Martin, A., J. S., Cammarata, A., 2008, Farmasi Fisika Jilid 2, Penerbit Universitas Indonesia (UI-Press), Jakarta.

Natasya, I., 2018, Formulasi Sediaan Mikroemulsi Ekstrak Etanol Teh Hijau (Camellia sinensis (L.) Kuntze), Skripsi, Universitas Sumatera Utara, Medan.

Nuryani, Y., 2006, Budidaya Tanaman Nilam (Pogostemon cablin Benth.), Balai Penelitian Tanaman Rempah dan Aromatik, Jakarta.

Pareta, D., N., 2016, Formulasi Self
Nanoemulsifying Drug Delivery System (SNEDDS) Minyak Atsiri Biji Pala (Mysristica fragrans Houtt), Tesis,Universitas Setia Budi,Surakarta.

Pratiwi, A.R., 2019, Formulasi Mikroemulsi Minyak Nilam: Kajian Stabilitas dan Antioksidan, Skripsi, Universitas Wahid Hasyim.

Priani, S. E., Abdilla, S. A., dan Suparnan, A., 2019, Pengembangan Sediaan Mikroemulsi Gel Antijerawat Mengandung Minyak Kulit Batang Kayu Manis (Cinnamomum burmanni Nees ex Bl), Jurnal Ilmiah Farmasi Farmasyifa, 3(1), 9-17.

Prihantini, M., 2018, Optimasi Formula Nanoemulsi Ganda A/M/A Ekstrak Etanol Daun Binahong dan Konjugat Asam Glikolat-Kitosan Menggunakan Desain Box-Behnken, Tesis, Universitas Institut Teknologi Bandung.

Putri, E.S.P.S.S., 2014, Pengaruh Perbandingan Surfaktan Tween 80 dan Kosurfaktan PEG 400 dalam Formulasi Sediaan Mikroemulsi Askorbil Palmitat dan Alfa Tokoferol Untuk Anti-Aging, Skripsi, Universitas Sanata Dharma, Yogyakarta.

Setya, N., Budiarti, A., Mahfud, 2012, Proses Pengamblan Minyak Atsiri dari Daun Nilam dengan Pemanfaatan Gelombang Mikro (Microwave), Jurnal Teknik ITS, Vol. 1 (1), F25F29.

Shetye, S.L., Jadhav. K.R., dan Kadam. V.J., 2010, Design and Evaluation of Microemulsion Based Drug Delivery System, Asian Journal Biology and Science, Department of Pharmaceutics Bharati Vidyapeeth's College of Pharmacy, CBD Belapur Mumbai, Vol. 1(3), 1-10.

Sisak, M.A.A., Daik, R., R. S., 2017, Study on the effect of oil phase and cosurfactant on mcroemulsion system, Malaysian Journal of Analytical Sciences, Vol. 21 (6), 1509-1416.

Smith, H., Idurs, S., Seimahuira, L.M., 2019, Kontribusi lama pemeraman daun dan modifikasi saringan ketel terhadap laju distilat dan rendemen minyak nilam asal Maluku, Majalah Biam, 15 (02), 106-113. 
Soh, S.H., Agarwal, S., Jayaraman, S., Tham, M.T., Lee, C.L.Y., Jain, A., 2018, A study of essential oil extraction and antioxidant activity of Patchouli (Pogostemon cablin) using supercritical carbon dioxide, ON12, 15.

Suprijono, A., Gunawan, Y., Wulan, A.H., 2015, Minyak Nilam sebagai Antioksidan dengan Metode DPPH, Jurnal Ilmu Farmasi dan Farmasi Klinik, Vol. 12 (1), 33-37.

Suryani, Putri, A.E.P., dan Agustyiani, P., 2017, Formulasi dan Uji Stabilitas Sediaan Gel Ekstrak Terpurifikasi Daun Paliasa (Kleinhovia hospita L.) Yang Berefek Antioksidan, Jurnal Imiah Farmasi, 6(3), 157 - 169.

Tisnadjaja, D., 2012, Pengkajian Aktivitas Antioksidan dari Beras Merah Hasil Fermentasi (angkak), Jurnal, Bogor : LIPI.

Wang, Y., 2014, Preparation of Nano- and
Microemulsion using Phase Inversion and Emulsion Titration Methods, Thesis, Master of Food and Technology, Massey University, 6 36.

Xu, F., Yang, Q., Wu, L., Qi, R., Wu, Y., Li, Y., Tang, L., Guo, D., Liu, B., 2017, Investigation of Inclusion Complex of Patchouli Alcohol with $\beta$ Cyclodextrin, Plos One, 12 (1), 1-10.

Yuwanti, S., S. Raharjo, P. Hastuti., dan Supriyadi, 2011, Formulasi Mikroemulsi Minyak dalam Air (O/W) yang Stabil Menggunakan Kombinasi Tiga Surfaktan Non Ionik dengan Nilai HLB Rendah, Tinggi, dan Sedang, Agritech, 31, 21 - 29.

Zhao, Z., Lu, L.K.L., Chan, J.C.H., dan Jiang, Z.H., 2005, Determination of Pathchouli Alcohol in Herba Pogostemonis by GC-MS-MS, Journal Chemistri Pharmacy Bull, 53(7), $856-860$.

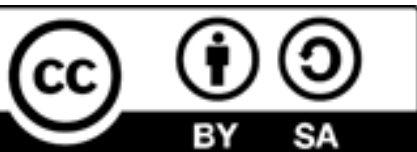

